\title{
Neurological and adrenal dysfunction in the adrenal insufficiency/alacrima/achalasia (3A) syndrome
}

\author{
D B Grant, N D Barnes, M Dumic, M Ginalska-Malinowska, P J Milla, W v Petrykowski, \\ R J Rowlatt, R Steendijk, J H K Wales, E Werder
}

\begin{abstract}
Review of 20 patients with glucocorticoid deficiency (three cases also with salt loss) associated with absent tear secretion (19 cases) and achalasia of the cardia (15 cases) revealed neurological abnormalities in 17 including hyper-reflexia, muscle weakness, dysarthria, and ataxia together with impaired intelligence and abnormal autonomic function, particularly postural hypotension. These findings indicate that significant neurological problems are common in this multisystem disorder. (Arch Dis Child 1993; 68: 779-782)
\end{abstract}

Familial glucocorticoid deficiency associated with achalasia of the cardia and deficient tear production was described in 1978 by Allgrove et al. ${ }^{1}$ Since then there have been a number of reports of similar cases. ${ }^{2-5}$ More recent reports indicate that there may be impairment of autonomic function in the condition ${ }^{67}$ and motor and sensory neuropathy have also been described, ${ }^{89}$ together with ataxia, optic atrophy and impaired intelligence, ${ }^{10} 11$ indicating that the dis-

Hospital for Sick Children, London

D B Grant

P J Milla

Addenbrooke's Hospital, Cambridge

N D Barnes

University Hospital Rebro, Zagreb, Croatia M Dumic

Child Health Centre, Warsaw, Poland M Ginalska-Malinowska

Universitäts-Kinderklinik, Freiburg, Germany W v Petrykowski

Furness General Hospital, Barrow in Furness R J Rowlatt

Academic Medical Centre, Amsterdam, The Netherlands R Steendijk

Children's Hospital, Sheffield

J H K Wales

Kinderspital Zurich, Switzerland

E Werder

Correspondence to: Dr D B Grant, Hospital for Sick Children, Great Ormond Street, London WCIN 3JH.

Accepted 20 January 1993 and family history.

In some families siblings have died in early infancy, probably as a result of adrenal insufficiency. These have not been included in the study as little information is available on their neurological status.

\section{Results}

Twenty patients ( 13 males, seven females) aged from 2.5 to 29.0 years at last follow up were identified. Their clinical details are summarised in the table. All have evidence of impaired cortisol secretion. Fourteen also have both alacrima that has been present from early infancy and achalasia of the cardia. Six patients have incomplete forms of the syndrome. Five have alacrima without achalasia (cases 16, 17, 18, 19, 20 ) and one has achalasia but normal tear secretion (case 7).

Earlier findings in 11 of the patients have been published previously. ${ }^{12-17}$

\section{ADRENAL INSUFFICIENCY \\ Cortisol deficiency}

Evidence of cortisol deficiency was present in all cases (table) and was diagnosed between the ages of 1.8 and 10.0 years on the basis of an absent plasma cortisol response to 1-24 corticotrophin (ACTH) (14 cases), absence of a rise in urinary cortisol metabolites after ACTH stimulation (one case), persistently low unstimulated concentrations of plasma cortisol (one case), and/or marked increase of plasma ACTH (14 cases). At the time of diagnosis four of these latter patients showed a significant rise in plasma cortisol after injection of 1-24 ACTH.

The age at which symptoms of adrenal insufficiency began ranged from 1.0 to 8.3 years. In 16 cases the initial symptoms were related to recurrent hypoglycaemia, usually associated with increased skin pigmentation. Two patients presented with vomiting (cases 9,15 ). In two cases, both with affected siblings, there were no symptoms of cortisol deficiency (cases 6,16 ). When restudied 9.2 years later at the age of 13.7 years one of these patients (case 6) still had a significant rise in plasma cortisol after injection of 1-24 ACTH but plasma ACTH remained raised.

With on exception, all the patients have been treated with oral hydrocortisone and have remained free from further episodes of hypoglycaemia. In one patient who had no symptoms (case 16) the parents refused to allow steroid replacement therapy.

\section{Aldosterone deficiency}

Three patients showed evidence of salt loss at the time of diagnosis. In one (case 14) plasma sodium 
Clinical findings in 20 patients with the $3 A$ syndrome

\begin{tabular}{|c|c|c|c|c|c|c|c|c|c|c|c|c|c|c|c|c|c|c|c|c|}
\hline & 1 & 2 & 3 & 4 & 5 & 6 & 7 & 8 & 9 & 10 & 11 & 12 & 13 & 14 & 15 & 16 & 17 & 18 & 19 & 20 \\
\hline \multicolumn{21}{|l|}{$\begin{array}{l}\text { Reference to previous } \\
\text { publication }\end{array}$} \\
\hline & $M$ & $\mathrm{~F}$ & $\mathrm{~F}$ & $\mathrm{M}$ & $M$ & $M$ & $\mathrm{~F}$ & M & $M$ & $\mathrm{~F}$ & $M$ & $M$ & $M$ & $M$ & M & $\mathrm{F}$ & $\mathrm{F}$ & $M$ & $M$ & $\mathrm{~F}$ \\
\hline Age last seen (years) & 29 & 25 & 23 & 23 & 22 & 20 & 17 & 17 & 16 & 13 & 12 & 12 & 11 & 9 & 9 & 6 & 5 & 4 & 2 & 2 \\
\hline Cortisol deficiency & + & + & + & + & + & $\mathbf{L}$ & + & + & + & + & + & + & + & + & + & $\mathrm{L}$ & + & + & + & + \\
\hline Salt loss & - & - & - & - & - & - & - & - & - & - & - & - & - & + & + & - & + & - & - & - \\
\hline Alacrima & + & + & + & + & + & + & - & + & + & + & + & + & + & + & + & + & + & + & + & + \\
\hline Achalasia & + & + & + & + & + & + & + & + & + & + & + & + & + & + & + & - & - & - & - & - \\
\hline \multicolumn{21}{|l|}{ Neurological dysfunction } \\
\hline Hyper-reflexia & + & + & + & + & + & + & + & - & + & + & - & - & + & + & - & - & + & + & + & - \\
\hline Increased tone & + & + & - & - & - & - & + & + & + & + & + & - & - & - & - & - & + & + & + & - \\
\hline Muscle weakness/wasting & + & - & - & + & + & - & + & - & + & - & + & - & + & + & - & - & + & - & - & - \\
\hline Extensor plantar responses & + & + & - & + & + & + & + & - & + & - & - & + & - & - & - & - & - & - & + & - \\
\hline Dysarthria/nasal speech & - & + & + & + & + & - & + & - & - & + & + & - & - & - & - & - & + & - & - & - \\
\hline Ataxia/clumsiness & - & - & - & - & - & - & + & + & + & + & + & + & - & - & - & - & - & - & - & - \\
\hline Sensory impairment & - & - & - & + & + & + & - & - & - & + & - & - & + & - & - & - & - & - & - & - \\
\hline \multicolumn{21}{|l|}{ Autonomic dysfunction } \\
\hline Postural hypotension & - & - & - & + & + & + & + & + & - & + & + & - & - & - & - & - & + & - & - & - \\
\hline Unequal pupils & - & - & - & - & - & - & + & + & - & - & - & - & - & + & - & + & - & - & + & - \\
\hline Absent/reduced sweating & - & + & - & + & NT & NT & NT & - & - & + & + & - & - & - & - & - & - & - & - & - \\
\hline Abnormal heart reflexes & NT & NT & NT & + & - & + & + & - & - & - & - & NT & NT & NT & - & - & + & - & - & - \\
\hline Abnormal methacholine test & NT & NT & NT & + & NT & + & NT & NT & NT & NT & NT & NT & + & NT & - & NT & + & NT & NT & NT \\
\hline Abnormal histamine test & $\mathrm{NT}$ & NT & $\mathrm{NT}$ & - & $\mathrm{NT}$ & + & NT & $\mathrm{NT}$ & $\mathrm{NT}$ & $\mathrm{NT}$ & $\mathrm{NT}$ & - & + & NT & - & NT & NT & NT & NT & NT \\
\hline Mental retardation & + & + & + & + & + & - & + & - & + & + & + & - & SLD & - & - & - & + & - & - & - \\
\hline \multicolumn{21}{|l|}{ Skin changes } \\
\hline Fissured palms & - & - & - & + & - & + & - & + & + & + & + & + & + & - & - & - & + & + & - & - \\
\hline Cutis anserina & - & - & - & - & - & - & + & + & + & + & + & + & - & - & - & - & + & - & + & - \\
\hline
\end{tabular}

Present $=+$, absent $=-; \mathrm{NT}=$ not tested $; \mathrm{SLD}=$ specific learning deficit $\mathrm{L}=$ latent .

concentration was $132 \mathrm{mmol} / \mathrm{l}$ and potassium $6 \cdot 0$ $\mathrm{mmol} / \mathrm{l}$. In the second (case 15 ), plasma sodium was $123 \mathrm{mmol} / \mathrm{l}$, urine sodium $62 \mathrm{mmol} / \mathrm{l}$, and plasma renin activity was markedly increased. In the third (case 17) plasma sodium fell to 128 $\mathrm{mmol} / \mathrm{l}$ and plasma renin activity rose to an abnormally high value after four days on a low sodium diet. All three patients have been treated with $9 \alpha$-fludrohydrocortisone and have shown a satisfactory response.

\section{ALACRIMA}

Nineteen patients have had alacrima since early infancy and most have required 'artificial tears' to avoid discomfort. Only one patient has apparently normal tear secretion (case 7).

\section{ACHALASIA OF THE CARDIA}

Fifteen patients have achalasia of the cardia, diagnosed between the ages of $2 \cdot 5$ and 17.0 years (table). In four cases $(7,8,10,11)$ the diagnosis of achalasia was made 1.0 to 4.3 years before the diagnosis of cortisol deficiency. There is considerable variation in the ages at which symptoms of achalasia were first noted, ranging from 0.5 to 16.0 years. Eleven patients have required one or more surgical procedures (Heller's operation), two have been treated by dilatation, and two have been managed with medical treatment.

Of the five cases without achalasia (table), one is a 6.7 year old girl (case 16) who had an older brother with alacrima and cortisol deficiency who first developed symptoms of achalasia at the age of 6.0 years. This girl also has 'latent' cortisol deficiency and is not on steroid therapy. The other four cases without achalasia are aged $2 \cdot 6$ to $5 \cdot 5$ years.

\section{NEUROLOGICAL FINDINGS}

Seventeen patients are considered to have evidence of neurological impairment (table), often with a mixed pattern of upper and lower motor neurone dysfunction. The most common findings were of hyper-reflexia (15 cases), increased limb tone (10 cases), extensor plantar responses (nine cases), and muscle weakness and/or wasting (nine cases). Dysarthria/nasal speech (eight patients), ataxia or clumsiness (six patients), and sensory impairment (five patients) were also recorded as were optic atrophy (cases 3 and 5), nerve deafness (case 12), and recurrent seizures (case 2). The ages at which these abnormal findings were first noted ranged from 2.4 to 15.5 years (median age 10.0 years). In general, abnormal neurological findings were more common in the older patients, and the three cases with no abnormalities were aged 2,6 , and 9 years, respectively. In the older patients the neurological disorder appeared to be either very slowly progressive or static at their last review.

\section{NERVE CONDUCTION STUDIES}

Nerve conduction studies were carried out in 11 patients (table); evidence of denervation was present in six.

\section{AUTONOMICAL DISTURBANCE}

Impaired autonomic function was a feature in 11 patients (table). Postural hypotension was present in eight cases, inequality of the pupils in five, absent or reduced sweating in four, and impotence in one (case 5). Of the 14 cases who had evaluation of their cardiac reflexes, four had abnormal results. The dermal flare response to histamine was assessed in only five patients and was abnormal in two. Methacholine tests were carried out in five cases; four were abnormal.

\section{IMPAIRED INTELLECT}

Eleven patients have some degree of intellectual impairment. Six of the seven patients who have 
had formal tests of psychometric function have IQ scores between 68 and 84 and one patient with an above average IQ score (113) has specific learning disabilities and is making poor progress at school. Three of the patients who have not had formal IQ tests have been unable to attend normal school because of moderate retardation and the fourth is making poor progress at school. The remaining nine patients are considered to be of normal intelligence but none has had a formal psychometric assessment.

\section{SKIN CHANGES}

Skin abnormalities are present in 12 patients. Ten have hyperkeratosis of the palms of their hands with multiple fine fissures, and eight have cutis anserina (table).

\section{OTHER FEATURES}

One patient has had multiple nasal polyps (case 1), one has scoliosis (case 12), and one cleft palate (case 19).

\section{FAMILY HISTORY}

There are three pairs of siblings in the present study (cases 4 and 6, 8 and 16, and 10 and 11). Seven further siblings (four males, three females) have died in early childhood, probably as a result of adrenal insufficiency. Seventeen siblings (seven males, 10 females) are alive and well with no clinical features of the syndrome.

None of the parents are consanguineous or show features of the disorder. However, a maternal great grandmother and maternal grandfather of case 1 had alacrima and skin pigmentation but were otherwise healthy.

\section{Discussion}

As would be expected in view of the method of case ascertainment, all the patients in this study show evidence of impaired cortisol secretion, and their clinical features are very similar to those described in other conditions associated with cortisol deficiency. Hypoglycaemia - often associated with addisonian skin pigmentation was usually the presenting symptom, starting before the age of 5 years in most cases and almost invariably before the age of 10 years.

At the time of diagnosis, four children appeared to have incomplete cortisol deficiency, as there was a significant rise in plasma cortisol after 1-24 ACTH stimulation. In these patients the diagnosis of cortisol deficiency was based on the presence of abnormally raised concentrations of endogenous ACTH. In one of these subjects (case 6) there was still a cortisol response to 1-24 ACTH when he was retested at the age of 13 years, suggesting that persistent incomplete cortisol deficiency can occur in the disorder. However, Moore et al noted progressive loss of cortisol secretion in one of their patients between the ages of 23 and 29 years, ${ }^{11}$ and complete glucocorticoid deficiency may eventually develop in our patient.

While most of our patients appear to have isolated cortisol deficiency, three also have evidence of aldosterone deficiency. These findings are in keeping with previously published results in other patients with this disorder that indicate that most have normal mineralocorticoid function but that salt loss may be present in some cases. ${ }^{2}$

The relationship between the adrenal disorder in our patients and those with classical 'ACTH unresponsiveness' who have isolated glucocorticoid deficiency ${ }^{18} 19$ is uncertain. However, both conditions are probably inherited as autosomal recessive disorders and cause progressive (and usually selective) loss of cortisol secretion in early childhood. ${ }^{20}$

The high incidence of enteric neurological abnormality in our patients is very striking. Achalasia of the cardia, diagnosed between the ages of 2 and 17 years, was present in 15. As in most of the other published cases, the diagnosis was usually made after - or at the same time - as that of cortisol deficiency. However, in four cases the diagnosis of achalasia preceeded the diagnosis of cortisol deficiency by one to four years. Five of our patients do not currently have any evidence of achalasia but one of them has an older sibling with the disorder and the others are still less than 6 years old. It remains to be seen whether they will go on to develop achalasia.

In a series of 35 children with achalasia of the cardia Nihoul-Fékété et al found only one with alacrima and cortisol deficiency, ${ }^{21}$ indicating that most children with achalasia have normal adrenal function. However, our results emphasise the importance of checking cortisol secretion if achalasia is associated with absent tear secretion or any of the neurological features described above.

The relationship between our patients and other cases of familial achalasia and alacrima with normal cortisol secretion ${ }^{22-24}$ is uncertain, as is the relationship with familial achalasia associated wth mental retardation and microcephaly. ${ }^{25}$ However, in these latter syndromes neurological and autonomic impairment have not been described, and they may represent different entities.

In the present study abnormalities of the nervous system were often associated with impaired intellect. In most of our patients the neurological findings were first recorded at the time of diagnosis of cortisol deficiency or some years later, usually after the onset of achalasia. While this suggests that central neurological disorder might be a relatively late manifestation in the $3 \mathrm{~A}$ syndrome, it is possible that the more subtle neurological features were not detected in early childhood.

The nature of the abnormal neurological features described above is of interest as they indicate that both central and peripheral neurones may be affected, and the findings are similar to those in subacute combined degeneration of the cord. ${ }^{17}$ The natural history of this neurological dysfunction is still not completely clear but our experience suggests that it is slowly progressive but may become static in adult life. Abnormalities of autonomic function were also common in our patients. The most disabling symptom was that of postural hypotension but in one subject impotence was a source of distress.

As there are many known similarities between 
the enteric and central nervous systems ${ }^{26}$ it seems very likely that the alacrima, autonomic dysfunction, and abnormalities of the central nervous system have an origin in common with the achalasia that is caused by a denervating process affecting primarily the myenteric plexus. ${ }^{27}$

Our observations indicate that the $3 \mathrm{~A}$ syndrome may also be associated with changes in the skin. Ten of the patients have mild hyperkeratosis of the palms with large numbers of fine fissures and eight have 'cutis anserina'.

Several of our patients have siblings with the disorder, some of whom died in early infancy before detailed investigation could be carried out. This finding, and the relatively even sex ratio, support the view that the disorder is transmitted by autosomal recessive inheritance. It is possible that all the features of the $3 \mathrm{~A}$ syndrome are due to deletion of autosomal DNA with loss of closely linked genes necessary for normal adrenocortical and neural function, and dermal keratinisation. Alternatively, both the neurological and adrenal pathology could be the result of an as yet undetermined metabolic error, or the adrenal failure could be related to degeneration of its autonomic nerve supply.

1 Allgrove J, Clayden GS, Grant DB, McCauley JC. Familial glucocorticoid deficiency with achalasia of the cardia and deficient tear production. Lancet 1978; i: 1284-6.

2 Lanes R, Plotnick LP, Byrum TE, et al. Glucocorticoid and partial mineralocorticoid deficiency associated with achalasia. 7 Clin Endocrinol Metab 1980; 50: 268-70.

3 Geffner ME, Lippe BM, Kaplan SA, et al. Selective ACTH insensitivity, achalasia, and alacrima: a multi-system disorder presenting in childhood. Pediatr Res 1983; 17:532-6.

4 Roubergue A, Beauvaus P, Gourmelen M, Richardet JM Insuffisance isolée en glucocorticoïdes avec achalasie et Insuffisance isolée en glucocorticoïdes avec
alacrymie. Ann Pediatr (Paris) 1986; 33: 321-4.

5 Ambrosiano MM, Geneiser NB, Bangaru BS, Sklar C, Becker MH. The syndrome of achalasia of the esophagus, ACTH insensitivity and alacrima. Pediatr Radiol 1986; 16: 328-9.

6 Pombo M, Devesa J, Tabarda A, et al. Glucocorticoid deficiency with achalasia of the cardia and lack of lacrimation. Clin Endocrinol (Oxf) 1985; 23: 237-43.

7 Makari G, Hoffman WH, Caroll JE, Savage DR, Van der Zalm T. Autonomic dysfunction and adrenocortical unresponsiveness to ACTH. F Child Neurol 1988; 3: 174-6.
8 Esposti AD, Ambrosiani G, Giardira A, et al. Sindrome familiare di ipoglicocorticismo da insensibilita all'ACTH con associata neurommiopatica distale. Minerva Med 1985 37: 353-9.

9 Stuckey BG, Mastaglia FL, Reed WD, Pullan PT. Glucocorticoid insufficiency, achalasia, alacrima with autonomic and motor neuropathy. Ann Intern Med 1987; 106: 62-4.

10 Ehrlich E, Aranoff G, Johnson WG. Familial achalasia associated with adrenocortical insufficiency, alacrima, and neuro-

11 Moore PSJ, Couch RM, Perry YS, Schuckett EP, Winter JSD Allgrove syndrome: an autosomal recessive syndrome of ACTH insensivity, achalasia and alacrima. Clin Endocrino Oxf) 1991; 34: 107-14.

12 Petrykowski W, Burmeister P, Böhm N. Familiäre Glucocorticoidinsuffizienz. Klin Pädiatr 1975; 187: 198-215.

13 Werder EA, Haller R, Vetter W, Zachmann M, Siebenmann R. Isolated glucocorticoid insufficiency. Helvetica Paediatrica Acta 1975; 30: 175-83.

14 Dumic M, Radica A, Jusic A, Stefanovic N, Murko Z. Selective ACTH insensitivity with autonomic nervous system disorders and sensory polyneuropathy. Eur $\mathcal{F}$ Pediatr 1987; 146: $592-4$.

15 Dumic M, Radica A, Sabol Z, et al. Adrenocorticotropic hormone insensitivity associated with autonomic nervous system disorders. Eur f Pediatr 1991; 150: 696-9.

16 Chrzanowska B, Romer TE, Baka-Jakubiak M, Kansy J. The syndrome of adrenocortical unresponsiveness to $\mathrm{ACTH}$ with achalasia. Endokrynologia Polska 1987; 38: 107-15.

17 Grant DB, Dunger DB, Smith I, Hyland K. Familial glucocorticoid deficiency with achalasia of the cardia, associated with mixed neuropathy, long tract degeneration and mild dementia. Eur F Pediatr 1992; 151: 85-9.

18 Shepard TH, Landing BH, Mason DG. Familial Addison's disease: case report of two sisters with corticoid deficiency unassociated with hypoaldosteronism. Am F Dis Child 1959; 97: $154-62$.

19 Migeon CJ, Kenny FM, Kowarski A, et al. Syndrome of congenital adrenocortical unresponsiveness to ACTH congenital adrenocortical
Pediatr Res $1968 ; 2: 501-13$.

20 Moshang T, Rosenfield RL, Bongiovanni AM, Parks JS, Amrhein JA. Familial glucocorticoid insufficiency. F Pediat 1973; 82: 821-6

21 Nihoul-Fékété C, Bawab F, Lortat-Jacob S, Arhan P, Pellerin $P$. Achalasia of the esophagus in childhood: surgical treatment in 35 cases with special reference to familial cases and glucocorticoid association. F Pediatr Surg 1989; 24: 1060-3.

22 Efrati Y, Mares AJ. Infantile achalasia associated with deficient tear production. 7 Clin Gastroenterol 1985; 7: 413-5.

23 Nussinson E, Hager H, Samara M, Bar-Nathan N, Slipovich L. Familial achalasia with absent tear production. $\mathcal{F}$ Pediatr Gastroenterol Nutr 1988; 7: 284-7.

24 Haverkamp F, Zerres K, Rosskamp R. Three siblings with achalasia and alacrima: a separate entity different from riple-A syndrome. Am f Med Genet 1989; 34: 289-91.

25 Khalifa MM. Familial achalasia, microcephaly and mental retardation. Clin Pediatr (Phila) 1988; 27: 509-12.

26 Furners JB, Costa M. The enteric nervous system. New York Churchill Livingstone, 1987.

27 Qualman SJ, Haupt HM, Yong P, Hamilton SR. Esophageal Lewy bodies associated with ganglion cell loss in achalasia. Gastroenterology 1984; 87: 848-56. 